\title{
PAISAGEM E GEOGRAFIA FÍSICA GLOBAL. ESBOÇO METODOLÓGICO'1
}

\author{
Georges BERTRAND
}

"Paisagem" é um termo pouco usado e impreciso, e por isto mesmo, cômodo, que cada um utiliza a seu bel prazer, na maior parte das vezes anexando um qualificativo de restrição que altera seu sentido ("paisagem vegetal", etc.). Emprega-se mais o termo "meio", mesmo tendo este termo outro significado. $\mathrm{O}$ "meio" se define em relação a qualquer coisa; este termo é impregnado de uma finalidade ecológica que não é encontrada na palavra "paisagem". ${ }^{2}$

O problema é de ordem epistemológica. Realmente, o conceito de "paisagem" ficou quase estranho à geografia física moderna e não tem suscitado nenhum estudo adequado. É verdade que uma tal tentativa implica numa reflexão metodológica e pesquisas específicas que escapam parcialmente à geografia física tradicional. Esta é, com efeito, desequilibrada pela hipertrofia da pesquisa geomorfológica e por graves carências, em particular no domínio das ciências biogeográficas. Enfim, ela permanece essencialmente analítica e "separativa", qualificativo emprestado de P. PÉDELABORDE que opõe a climatologia clássica "separativa" (estudo das temperaturas, das precipitações, etc.) à climatologia "di- nâmica" (estudo global das massas de ar) ${ }^{3}$ enquanto que o estudo das paisagens não pode ser realizado senão no quadro de uma geografia física global.

A paisagem não é a simples adição de elementos geográficos disparatados. É, em uma determinada porção do espaço, o resultado da combinação dinâmica, portanto instável, de elementos físicos, biológicos e antrópicos que, reagindo dialeticamente uns sobre os outros, fazem da paisagem um conjunto único e indissociável, em perpétua evolução. A dialética tipo-indivíduo é próprio fundamento do método de pesquisa.

É preciso frisar bem que não se trata somente da paisagem "natural" mas da paisagem total integrando todas as implicações da ação antrópica. No entanto, deixaremos provisoriamente de lado as paisagens fortemente urbanas que, criando problemas originais, determinam possivelmente, para alguns de seus aspectos, métodos análogos.

Estudar uma paisagem é antes de tudo apresentar um problema de método.

1 Tradução: Olga Cruz. Trabalho publicado, originalmente, na "Revue Geógraphique des Pyrénées et du Sud-Ouest", Toulouse, v. 39 n. 3, p. 249-272, 1968, sob título: Paysage et geographie physique globale. Esquisse méthodologique. Publicado no Brasil no Caderno de Ciências da Terra. Instituto de Geografia da Universidade de São Paulo, n. 13, 1972.

2 Meio: "Espaço que envolve imediatamente as células ou os organismos vivos e com o qual os seres vivos realizam trocas constantes de matéria e de energia". Grand Larousse Encyclopédique, t. 7, p. 358.

3 PEDELABORDE, P. Introduction à l'étude scientifique du climat. Paris: C.D.U., 1995. p. 3. 
A exposição que se segue dá ênfase sucessivamente a problemas de taxonomia, de dinâmica, de tipologia e de cartografia das paisagens.

\section{A ANÁLISE DA PAISAGEM}

A noção de escala é inseparável do estudo das paisagens. As escalas temporo-espaciais de inspiração geomorfológica de A. CAILLEUX e J. TRICART foram utilizadas como base geral de referência para todos os fenômenos geográficos (a ordem de grandeza é indicada entre parêntesis, abreviada G. I, G. II, G. III). ${ }^{4}$

1 -As classificações elementares - cada disciplina especializada no estudo de um aspecto da paisagem se apóia em um sistema de delimitação mais ou menos esquemático formado de unidades homogêneas (ao menos em relação à escala considerada) e hierarquizadas, que se encaixam umas nas outras. A classificação fitogeográfica de H. GAUSSEN: ANDAR (ex. mediterrâneo) - SÉRIE (ex. carvalho verde) ESTÁDIO (ex. garrigue) é a melhor ilustração disso. Em qualquer dos casos, trata-se de unidades específicas que podem ser qualificadas de "elementares" em relação ao complexo formado pela paisagem. Esses sistemas são tão variados quanto numerosos; nós não reteremos senão os que apresentam um interesse do ponto de vista da taxonomia das paisagens.

As classificações climáticas e pedológicas são também tão gerais como teóricas e, além disso, são bastante discutíveis. A hierarquia bem conhecida desde Max Sorre: clima zonal (G. I), clima regional (G. I a G. IV), clima local (G. V - G. VI) e microclima (G. VII), pode fornecer um primeiro ponto de partida. Os geomorfologistas nunca demonstraram muito interesse por questões taxonômicas. Podendo citar somente a classificação morfo-estrutural apresentada por G. VIERS conforme os trabalhos de J. TRICART: o domínio estrutural (ex. Europa herciniana, G. III) a região estrutural (ex. as Ardenas, G. IV) - a unidade estrutural (ex. um anticlinal pré-alpino, G. V). ${ }^{5}$ A bacia-vertente, unidade hidro-geomorfológica, corresponde a uma descontinuidade essencial da paisagem, mas ela é heterogênea por definição e o limite à jusante é sempre difícil de ser estabelecido. Enfim, as paisagens ditas "físicas" são com efeito quase sempre amplamente remodeladas pela exploração antrópica. A divisão em parcelas, territórios, comunidades, quarteirões e "pays" vai então constituir um dos critérios essenciais da taxonomia das paisagens. ${ }^{6}$

No entanto, a melhor aproximação do problema é fornecida pela vegetação que se comporta sempre como verdadeira síntese do meio. As unidades fitogeográficas citadas acima (andar-série-estádio) correspondem a massas vegetais perfeitamente definidas tanto no plano fisionômico quanto no plano dinâmico. A fitosociologia moderna com orientação sinecológica vem harmoniosamente completar este sistema, permitindo delimitar unidades homogêneas do ponto de vista florístico (associações e agrupamentos vegetais, G. VI a G. VII).

Como era de se esperar, essas diversas classificações elementares não têm entre elas nenhuma relação lógica porque os fenômenos em causa pertencem a ordens geográficas diferentes. Certos especialistas realizaram reagrupamentos parciais que constituem já uma $1^{a}$ etapa para a definição das paisagens. Nesse domínio, os biogeógrafos, já há muito tempo, precederam os geógrafos.

2-As combinações bio-ecológicas -A biocenose

é

um agrupamento de seres vivos, correspondendo, pela composição e pelo número das espécies e dos indivíduos, a certas condições médias do meio, agrupamento de organismos, ligados por uma dependência recíproca que se mantém por reprodução de maneira permanente" 7

O pântano com rãs é um exemplo dessa combinação. A biocenose coloniza o biótopo que é a unidade elementar correspondente ao menor conjunto homogêneo do meio físico-químico (G. VII-VIII). O ecótopo, a biogeocenose, o microcosmo, o "holocoen", o "naturcomplex", o fisiótopo, a geoforma, etc., exprimem com algumas variações, e de diversas maneiras, uma realidade bem próxima. ${ }^{8}$

As unidades biogeográficas superiores, como a tundra, a savana, a floresta tropical úmida, são

4 TRICART, J. Principes et Méthodes de la Géomorphologie. Paris: Masson, 1965, p. 79-90. Ver também GLANGEAUD, L. Degré de régionalité. Bull Soc. Géol. Fr., 1952.

5 VIERS, G. Eléments de Géomophologie. Paris: Nathan, 1967, p. 27-29.

6 Terminologia utilizada por R. BRUNET nos estudos a serem publicados: La notion de quartier rural. Bull A.G. F., 1968 et Rev. Géogr. Pyr. S. - O., 1968.

7 ANGELIER, M. Cours de biogéographie animale, proferido no Centro do $3^{\circ}$ Ciclo de Biogeografia, da Faculdade de Ciências de Toulouse, 1963-1964.

8 Cf., mais particularmente, KORMONDY, E. S. Readings of ecology, New Jersey, 1965, 220 p. 
qualificadas de "biomas". São massas relativamente homogêneas de vegetais e de animais, em equilíbrio entre elas, e com o clima. As "zonas ecológicas equipotenciais" de P. REY poderiam servir de unidades intermediárias entre a biocenose e o bioma, tanto mais que elas tentam integrar certos dados geológicos e humanos (G. V-VI). Apoiando-se nessa noção de "equipotencialidade" ecológica e aplicando métodos de análises multifatoriais preconizadas por B. L. J. BERRY no domínio da pesquisa sócio-psicológica, M. PHIPPS tem a ambição de achar as estruturas da "paisagem biogeográfica" e de definir matematicamente um "modelo biogeográfico" da paisagem. ${ }^{9}$

Os biogeógrafos modernos foram ainda mais longe a caminho da síntese, definindo o "ecossistema". Acentuaram as cadeias e as redes tróficas, isto é, as ligações alimentares que unem os indivíduos e as comunidades vivas: "Qualquer que seja o ecossistema estudado, (...) trata-se sempre, em definitivo, de um problema de elaboração, de circulação, de acumulação e de transformação de energia potencial pela ação dos seres vivos e seu metabolismo". ${ }^{10}$ Entre as melhores aplicações desse sistema, em particular no plano cartográfico, é preciso citar os trabalhos dos norteamericanos, dos belgas, dos alemães, dos soviéticos e dos poloneses. ${ }^{11} \mathrm{O}$ ecossistema não tem nem escala nem suporte especial bem definido. Ele pode ser o oceano, mas também pode ser o pântano com rãs. Não é, portanto, um conceito geográfico. Nessas condições é melhor renunciar e reajustar a taxonomia biogeográfica, a escolher livremente unidades geográficas globais adaptadas ao estudo da paisagem. Diversas tentativas já foram realizadas nesse sentido.

3 - As primeiras sínteses geográficas - A "região natural" foi durante longo tempo o pilar da geografia francesa. "O termo de região se aplica (...) tanto a conjuntos físicos, estruturais ou climáticos como a domínios caracterizados pela sua vegetação". ${ }^{12}$ Realmente, a "região natural" escapa a toda definição racional tanto pelo conteúdo como pela superfície coberta (G. III à G. V). Pode-se conservar esta unidade maleável e cômoda com a condição de colocá-la em um sistema taxonômico coerente. De uma maneira geral, as sínteses de geografia física, realizadas durante a "idade de ouro" da geografia regional francesa, pecavam pela falta de cultura biológica e ecológica. É fora da França que devem ser procuradas as raras tentativas para apreender a paisagem na sua totalidade. Nós deixaremos por enquanto de lado todas as delimitações mais ou menos agronômicas ligadas ao "land-use" britânico ou ao "soil-survey" norte-americano.

A noção de "Landschaff" domina toda a geografia germânica. Desde a $2^{\mathrm{a}}$ metade do século XIX, uma "Landschaftskunde" tentou precisar as relações do homem e do meio. O determinismo abrupto desta ciência da paisagem arruinou completamente a iniciativa e certamente contribui a desviar os geógrafos franceses da ecologia, então em nascimento. ${ }^{13}$ Ele lançou as bases da "Landschaftsökologie" que é um estudo da paisagem do ponto de vista ecológico. As paisagens são divididas em "ecótopos" (ou em "landschaftzellen") que são unidades inteiramente comparáveis ao ecossistema. Este método representa um progresso decisivo sobre os estudos fragmentados dos geógrafos e dos biogeógrafos, porque ele reagrupa todos os elementos da paisagem, e o lugar reservado ao fenômeno antrópico é bem importante nele. No entanto, trata-se mais de uma atitude de espírito do que de um método de estudo cientificamente estabelecido. A definição dos "ecótopos" permanece imprecisa e a hierarquização dos fatores não é evocada. Nenhuma tipologia sistemática permite lançar claramente o problema da representação cartográfica. Trata-se em suma de um método mais ecológico que geográfico.

Pesquisadores soviéticos e americanos ultrapassaram por generalização o conceito de ecossistema e tentaram abordar as paisagens sob o aspecto estritamente quantitativo. (TROLL, 1966). A paisagem é considerada como um sistema energético cujo estudo se lança em termos de transformação e de produtividade bioquímica. Esta "geochemical landscape" enriquece e simplifica ao mesmo tempo a noção tradicional

9 REY, R. CABAUSSEL, ARLES, Les bases biogéographiques de la restauration forestière et pastorale dans de département de I' Aude-Corbières, Razès, Piegè. Toulousse, 1961 (C.N.R.S., Service de la carte de la vegétation, 39 p. ronéo) PHIPPS, M. Introduction au concept de modèle biogéographique. Actes $2^{\circ}$ Symposium Internat. Phot. Interprétation, Paris, 1966, v. 4, n. 2, p. 41-49.

10 DUVIGNEAUD, P.; TANCHE, M. Ecosystème et biosphère. L'écologie, science moderne de synthese (v. 2). Trav. Centre Ecologie générale, minist. Education Nationale, Bruselles, 1962, 127 p.

11 Entre outros citemos: CROWLEY, J. M.; JURDANT, M.; KUCHLER, A. W.; SHELDFORD, V. (Canadá, U.S.A.) J. SMITHUSEN, C. TROLL e R. TUXEN (Allemagne), P. DUVIGNEAUD (Belgique), ICHACHENKO, NEOSTRUEV, PALYNOV, SOTCHAVA, VILENSKY, VINK, etc. (U.R.S.S.), KONDRACKI (Pologne) et PLESNIK (Tchécoslovaquie). Ver mais particularmente J. M. CROWLEY, La Biogéographie vue par um géographe, C. R. som. Soc. Biogéographie, 1967, n. 380-382, p. 20-27.

12 CHOLLEN, A. La géographie guide de l' etudiant. Paris, 1951, p. 31.

13 TROLL, C. retomou esta idéia apoiando-se nos trabalhos dos ecologistas anglo-saxões, tirando proveito de sua própria experiência sobre foto-interpretação. TROLL, C. Landscape ecology. Public of the I.T.C UNESCO Centre for Integrated Surveys, 1966, Delft S. 4, 23 p. 
de "paisagem". Mas os próprios especialistas se perguntam como poderão medir (posta de lado, a fotossíntese) as transformações de energia ao nível de outros elementos que não os vegetais, particularmente ao nível da microfauna. Mesmo o cálculo aproximado do balanço energético de uma paisagem não é ainda possível. No momento, o principal interesse da "geochemical landscape" é chegar a uma tipologia dinâmica das paisagens em função da migração das substâncias geoquímicas. Distinguem-se 3 categorias de paisagens: um tipo "residual" (estável), um tipo de "trânsito" (perda de substância) e um tipo de "acumulação". Sob uma formulação diferente, reencontra-se a bioresistasia de $\mathrm{H}$. ERHART que certos geógrafos tentam adaptar à geografia física. ${ }^{14}$ Neste nível de concepção, a paisagem aparece como um objeto de estudo bem definido que apela para um ponto de vista metodológico.

\section{A SÍNTESE DA PAISAGEM}

Todas as delimitações geográficas são arbitrárias e "é impossível achar um sistema geral do espaço que respeite os limites próprios para cada ordem de fenômenos." 15 Contudo, pode-se vislumbrar uma taxonomia das paisagens com dominância física sob a condição de fixar desde já limites.

$\left.1^{\circ}\right)$ A delimitação não deve nunca ser considerada como um fim em si, mas somente como um meio de aproximação em relação com a realidade geográfica. Em lugar de impor categorias pré-estabelecidas, trata-se de pesquisar as descontinuidades objetivas da paisagem.

$2^{\circ}$ ) É preciso de uma vez por todas renunciar a determinar unidades sintéticas na base de um compromisso a partir das unidades elementares; seria certamente um mau método querer superpôr, seja pelo método cartográfico direto, seja pelo método matemático (sistema de rede), o máximo de unidades elementares para destacar daí uma unidade "média" que não exprimiria nenhuma realidade por existir a estrutura dialética das paisagens. Ao contrário, é pre- ciso procurar talhar diretamente a paisagem global tal qual ela se apresenta. Naturalmente a delimitação será mais grosseira, mas as combinações e as relações entre os elementos, assim como os fenômenos de convergência aparecerão mais claramente. $A$ síntese, no caso, vem felizmente substituir a análise.

$3^{\circ}$ ) O sistema taxonômico deve permitir classificar as paisagens em função da escala, isto é, situá-las na dupla perspectiva do tempo e do espaço. Realmente, se os elementos constituintes de uma paisagem são mais ou menos sempre os mesmos, seu lugar respectivo e sobretudo suas manifestações no seio das combinações geográficas dependem da escala temporo-espacial. Existem, para cada ordem de fenômenos, "inícios de manifestações" e de "extinção" e por eles pode-se legitimar a delimitação sistemática das paisagens em unidades hierarquizadas. ${ }^{16}$ Isto nos leva a dizer que a definição de uma paisagem é função da escala. No seio de um mesmo sistema taxonômico, os elementos climáticos e estruturais são básicos nas unidades superiores (G. I a G. IV) e os elementos biogeográficos e antrópicos nas unidades inferiores (G. V a G. VIII).

O sistema de classificação finalmente escolhido comporta seis níveis temporo-espaciais; de uma parte a zona, o domínio e a região; de outra parte, o geosistema, o geofácies e o géotopo (observar a tabela 1 - a seguir).

1 - As unidades superiores - As pesquisas têmse limitado às unidades inferiores. No entanto, pareceu necessário apresentar um sistema taxonômico completo. Para as unidades superiores, é suficiente retomar o sistema de delimitação consagrado pelo uso, precisando somente a definição e o lugar relativo de cada unidade.

O qualificativo de "zona" deve ser imperativamente ligado ao conceito de zonalidade planetária. É então reservado aos conjuntos de $1^{a}$ grandeza (zona

14 ERHART, H. La genèse des sols entant que phénomène géologique. Esquisse d'une théorie géologique et géochimique. Exemples d'application. Paris, 2. ed., 1967, 177 p.

15 CLAVAL, P. La division regionale de la Suisse. Rev. Géogr. de 1' Est, 1967, p. 83-94.

16 BRUNET, R. Les phénomènes de discontinuité en géographie (These complém. Toulouse, 1965, p. 22-28), sur ex-ronéo (Em vias de publicação no "Memoires e Documents du Centre de Recherches et Documentation cartogra-phiques et géographiques du C.N.R.S."). 
TABELA 1 -

\begin{tabular}{|c|c|c|c|c|c|c|c|}
\hline \multirow{2}{*}{$\begin{array}{l}\text { UNIDADES DA } \\
\text { PAISAGEM }\end{array}$} & \multirow[b]{2}{*}{$\begin{array}{c}\text { ESCALA } \\
\text { TEMPORO- } \\
\text { ESPACIAL (A. } \\
\text { CAILEUX J. } \\
\text { TRICART) }\end{array}$} & \multirow{2}{*}{$\begin{array}{l}\text { EXEMPLO TOMADO NUMA } \\
\text { MESMA SÉRIE DE } \\
\text { PAISAGEM }\end{array}$} & \multicolumn{5}{|c|}{ UNIDADES ELEMENTARES } \\
\hline & & & RELEVO (1) & Clima (2) & BOTÂNICA & BIOGEOGRAFIA & $\begin{array}{c}\text { UNIDADE } \\
\text { TRABALHADA } \\
\text { PELO HOMEM } \\
\text { (3) }\end{array}$ \\
\hline ZONA & $\begin{array}{c}\text { G I grandeza } \\
\text { G. I }\end{array}$ & Temperada & & Zonal & & Bioma & Zona \\
\hline DOMÍNIO & G. II & Cantábrico & $\begin{array}{l}\text { Domínio } \\
\text { estrutural }\end{array}$ & Regional & & & $\begin{array}{l}\text { Domínio } \\
\text { Região }\end{array}$ \\
\hline $\begin{array}{c}\text { REGIÃO } \\
\text { NATURAL }\end{array}$ & G. III-IV & Picos da Europa & $\begin{array}{l}\text { Região } \\
\text { estrutural }\end{array}$ & & $\begin{array}{l}\text { Andar } \\
\text { Série }\end{array}$ & & $\begin{array}{l}\text { Quarteirão rural } \\
\text { ou urbano }\end{array}$ \\
\hline GEOSSISTEMA & G. IV-V & $\begin{array}{l}\text { Atlântico Montanhês } \\
\text { (calcário sombreado com } \\
\text { faia higrófila a Asperula } \\
\text { odorata em "terra fusca") }\end{array}$ & $\begin{array}{l}\text { Unidade } \\
\text { estrutural }\end{array}$ & local & & $\begin{array}{c}\text { Zona } \\
\text { equipotencial }\end{array}$ & \\
\hline GEOFÁCIES & G. VI & $\begin{array}{c}\text { Prado de ceifa com } \\
\text { Molinio-Arrhenatheretea } \\
\text { em solo lixiviado } \\
\text { hidromórfico formado em } \\
\text { depósito morâinico }\end{array}$ & & & \begin{tabular}{|c|} 
Estádio \\
Agrupamen- \\
to
\end{tabular} & & $\begin{array}{l}\text { Exploração ou } \\
\text { quarteirão } \\
\text { parcelado } \\
\text { (pequena ilha } \\
\text { ou cidade) }\end{array}$ \\
\hline GEÓTOPO & G. VII & $\begin{array}{l}\text { "Lapiés" de dissolução } \\
\text { com Aspidium lonchitis } \\
\text { em microsolo úmido } \\
\text { carbonatado em bolsas }\end{array}$ & & Microclima & & $\begin{array}{c}\text { Biótopo } \\
\text { Biocenose }\end{array}$ & $\begin{array}{l}\text { Parcela (casa } \\
\text { em cidade) }\end{array}$ \\
\hline
\end{tabular}

NOTA: As correspondências entre as unidades são muito aproximadas e dadas somente a título de exemplo. 1 - conforme A. Cailleux, J. Tricart e G. Viers; 2 - conforme M. Sorre; 3 - conforme R. Brunet.

temperada). Na realidade, a zona se define primeiramente pelo seu clima e seus "biomas", acessoriamente por certas megaestruturas (os estudos das áreas tropicais...).

O "domínio" corresponde a unidade de $2^{\mathrm{a}}$ grandeza. O domínio mediterrâneo s.s. é um exemplo deste tipo com suas paisagens vigorosamente individualizadas. Da mesma maneira, define-se um domínio cantábrico caracterizado por uma certa combinação de relevos montanhosos e de climas oceânicos. A definição do domínio deve ficar suficientemente maleável para permitir reagrupamentos diferentes nos quais a hierarquia dos fatores pode não ser a mesma (domínio alpino, domínio atlântico europeu...).

A região natural, já apresentada, situa-se entre a $3^{\mathrm{a}}$ e $4^{\mathrm{a}}$ grandeza. Os Picos de Europa constituem, no interior do domínio cantábrico, uma região natural bem circunscrita que corresponde à individualização tectônica de um maciço calcário vigorosamente compartimentado e carstificado. Ele constituiu uma "frente montanhosa" hiperúmida e hipernebulosa caracterizado por um an- dar biogeográfico original (mistura faia-carvalho verde nas baixas encostas, ausência de resinosas, limites superior da floresta bem baixa, passagem da "terra fusca" oceânicas aos solos alpinos húmicos).

2 -As unidades inferiores - Foi necessário montar todas as peças das unidades globais inferiores à região natural. Após numerosos ensaios, forjaram-se 3 entidades novas: o geosistema, o geofácies e o geótopo. Estes termos têm a vantagem de não terem sido utilizados, de serem construídos em um modelo idêntico e de evocar cada um o traço característico da unidade correspondente. Na verdade, geo "sistema" acentua o complexo geográfico e a dinâmica de conjunto; geo "facies" insiste no aspecto fisionômico e geo "topo" situa essa unidade no ultimo nível da escala espacial. ${ }^{17}$

a) O geosistema - O exemplo de geosistema Sierras Planas (Espanha do noroeste, domínio cantábrico região dos picos de Europa). As Sierras Planas são plataformas escalonadas entre 180 e 450m de altitude entre o oceano Atlântico e o maciço Cantábrico. Talhadas no arenito e os quartzitos do primário, elas

$17 \mathrm{Em}$ um $1^{\circ}$ estudo consagrado à análise de um caso concreto (BERTRAND, G. Esquisse biogéographique de la Liébana, La dynamique actuelle des paysages, R.G.P.S. - O, 1964, fasc. 3, p. 225-262), havia-se utilizado um vocabulário diferente que tinha sido criticado por um certo número de especialistas. 
representam os vestígios de superfícies de aplainamento de idade miocênica que se ligam ao piemonte norte-cantábrico hoje em sua maior parte afundado e afogado sob o oceano. Esses planaltos, talhados em estreitas línguas, por sulcos de erosão plioquaternários, mergulham em um clima hiperoceânico particularmente úmido e nebuloso. As "landes" atlânticas partilham a superfície com as turfeiras oligotróficas de "Sphagnum" e "Polytricum". As Sierras Planas foram desmatadas e usadas como pastagens desde o neolítico. Atualmente, elas são sub-utilizadas: alguns pedaços para pastoreio, reflorestamentos recentes com Eucalyptus globulus e Pinus insignis, uma exploração arcaica da turfa. É uma paisagem nítida e bem circunscrita que se pode, por exemplo, identificar instantaneamente nas fotografias aéreas. Portanto as Sierras Planas se ligam a unidades elementares discordantes e de extensão variável: um piemonte complexo que franjeia toda a vertente norte-cantábrica, um clima comum ao conjunto do litoral asturiano, fenômenos de podzolização que são vistos em todas rochas matrizes quartzíticas das montanhas cantábricas, uma série vegetal dominada pelo carvalho pedunculado que cobre uma superfície muito mais vasta, enfim uma exploração silvo-pastoral, que não é muito diferente das encontradas nas regiões vizinhas. A unidade da paisagem é portanto incontestável. Ela resulta da combinação local e única de todos esses fatores (sistema de declive, clima, rocha, manto de decomposição, hidrologia das vertentes) e de uma dinâmica comum (mesma geomorfogênese, pedogênese idêntica, mesma degradação antrópica da vegetação que chega ao paraclimax "lande" podzol ou à turfeira). A paisagem das Sierras Planas caracteriza-se por uma certa homogeneidade fisionômica, por uma forte unidade ecológica e biológica, enfim, fato essencial, por um mesmo tipo de evolução. Este exemplo permite esboçar uma definição teórica do geosistema (vide figura 1 - abaixo).

O geosistema situa-se entre a $4^{\mathrm{a}}$ e a $5^{\mathrm{a}}$ grandeza temporo-espacial. Trata-se, portanto, de uma unidade dimensional compreendida entre alguns quilômetros quadrados e algumas centenas de quilômetros quadrados. É nesta escala que se situa a maior parte dos fenômenos de interferência entre os elementos da paisagem e que evoluem as combinações dialéticas mais interessantes para o geógrafo. Nos níveis superiores a ele só o relevo e o clima importam e, acessoriamente, as grandes massas vegetais. Nos níveis inferiores, os elementos biogeográficos são capazes de mascarar as combinações de conjunto. Enfim, o geosistema constitui uma boa base para os estudos de organização do espaço porque ele é compatível com a escala humana.

O geosistema corresponde a dados ecológicos relativamente estáveis. Ele resulta da combinação de fatores geomorfológicos (natureza das rochas e dos mantos superficiais, valor do declive, dinâmica das

FIGURA 1 - ESBOÇO DE UMA DEFINIÇÃO TEÓRICA DE GEOSSISTEMA.

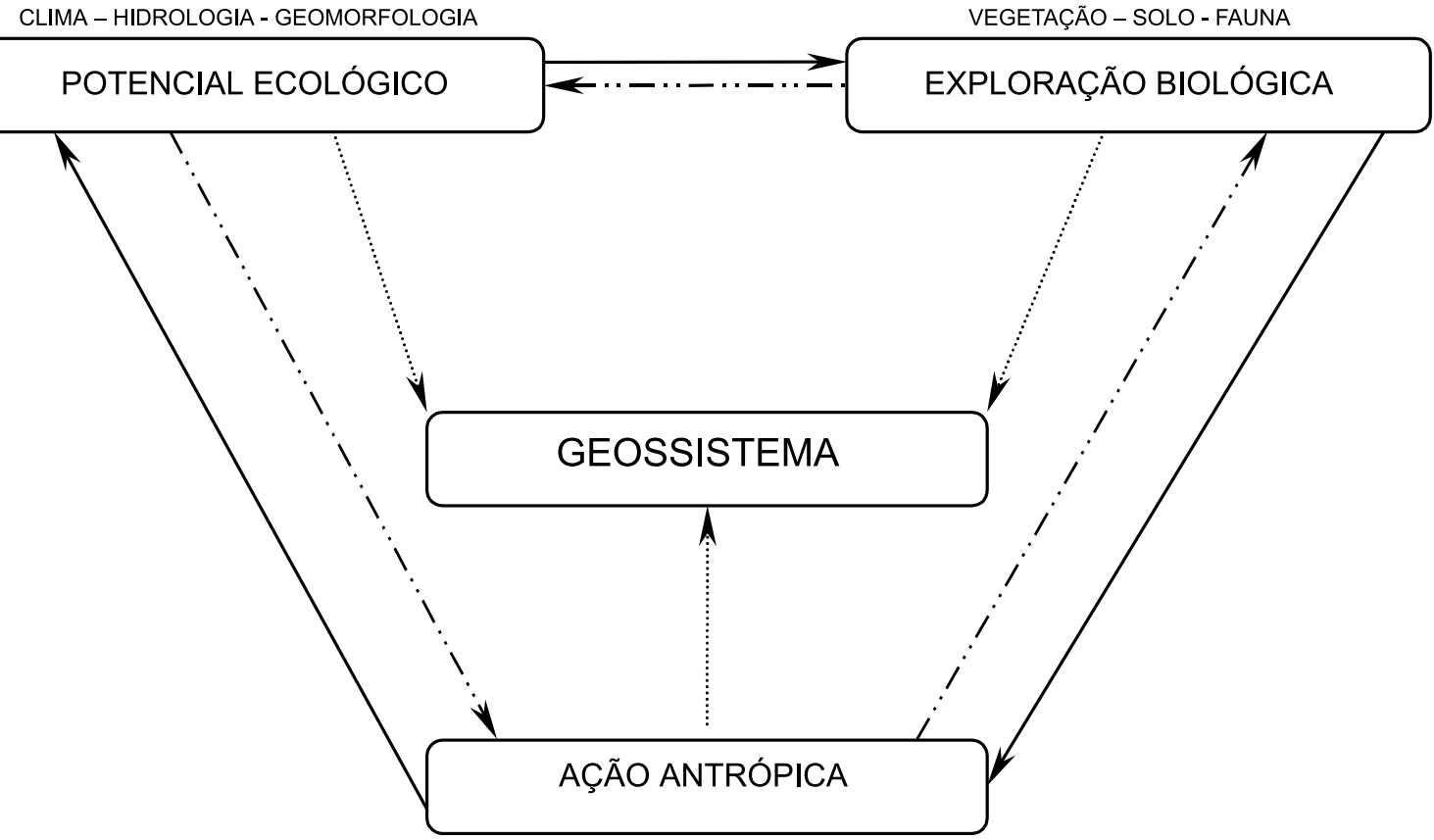


vertentes...), climáticos (precipitações, temperatura...) e hidrológicos (lençóis freáticos epidérmicos e nascentes, $\mathrm{pH}$ das águas, tempos de ressecamento do solo...). É o "potencial ecológico" do geosistema. Ele é estudado por si mesmo e não sob o aspecto limitado de um simples "lugar". Para uma soalheira calcária da média montanha pirenaica, por exemplo, as paredes talhadas no calcário urgoniano-aptiano da bacia de "Tarascon-Ariège", o potencial ecológico corresponde a vertentes recobertas de camadas de fragmentos rochosos, a uma insolação e a um aquecimento do substrato, superiores à média regional, enfim, à ausência de fontes e mesmo de todo o escoamento epidérmico. Pode-se admitir que existe, na escala considerada, uma sorte de "contínuo" ecológico no interior de um mesmo geosistema, enquanto que a passagem de um geosistema ao outro é marcada por uma descontinuidade de ordem ecológica.

O geosistema se define em seguida por um certo tipo de exploração biológica do espaço. A vertente Norte da Montanha Negra (SW do Maciço central), bem servida por chuvas, fresca e nebulosa, é colonizada por uma floresta de faia montanhosa com urzes, Asperula odorata, Melia como a flor, etc... em equilíbrio com solos brunos florestais de vertentes. Há uma relação evidente entre o potencial ecológico e a valorização biológica. No entanto, esta última depende também muito estreitamente do estoque florístico regional. Por exemplo, se o pinheiro pectíneo fosse espontâneo na Montanha Negra, a floresta de faia seria naturalmente substituída, seja por uma floresta de faia e pinheiro, seja mesmo por uma floresta de pinheiro pura, com Prenanthes purpurea em solos lixiviados ou em solos podzólicos.

O geosistema está em estado de clímax quando há um equilíbrio entre o potencial ecológico e a exploração biológica. A floresta de faia já citada realiza este equilíbrio. O potencial ecológico está de qualquer maneira "saturado" e o geosistema caracteriza-se por uma boa estabilidade de conjunto. Mas é um caso relativamente raro.

Com efeito, o geosistema é um complexo essencialmente dinâmico mesmo em um espaço-tempo muito breve, por exemplo, de tipo histórico. O "clímax" está longe de ser sempre realizado. O potencial ecológico e a ocupação biológica são dados instáveis que variam tanto no tempo como no espaço. A mobilidade biológica é bem conhecida (dinâmica natural da vegetação e dos solos, intervenções antrópicas, etc.). De outro lado, parece que os naturalistas se interessaram pouco pela evolução própria do potencial ecológico que precede, acompanha ou segue as modificações de ordem biológica. Por exemplo, a destruição de uma floresta pode contribuir para a elevação do lençol freático ou desencadear erosões susceptíveis de transformar radicalmente as condições ecológicas. As noções de "fator limitante" e de "mobilidade ecológica" merecem um exame aprofundado da parte do geógrafo advertido dos fenômenos de geomorfogênese e de degradação antrópica. ${ }^{18}$

Por essa dinâmica interna, o geosistema não apresenta necessariamente uma grande homogeneidade fisionômica. Na maior parte do tempo, ele é formado de paisagens diferentes que representam os diversos estágios da evolução do geosistema. Realmente, estas paisagens bem circunscritas são ligadas umas às outras por meio de uma série dinâmica que tende, ao menos teoricamente, para um mesmo clímax. Estas unidades fisionômicas se unem então em uma mesma família geográfica. São os geofácies (pl. VII A e B).

b) O geofácies e o geótopo: no interior de um mesmo geosistema, o geofácies corresponde então a um setor fisionomicamente homogêneo onde se desenvolve uma mesma fase de evolução geral do geosistema. Em relação à superfície coberta, algumas centenas de $\mathrm{Km}^{2}$ em média, o geofácies se situa na $6^{\mathrm{a}}$ grandeza de escalas de A. Cailleux e J. Tricart.

Assim como para o geosistema, pode-se distinguir em cada geofácies um potencial ecológico e uma exploração biológica. Nessa escala, é muitas vezes esta última que vem a ser determinação e que repercute diretamente na evolução do potencial ecológico. $O$ geofácies representa assim uma malha na cadeia das paisagens que se sucedem no tempo e no espaço no interior de um mesmo geosistema. Pode-se falar de cadeias progressivas e de cadeias regressivas de geofácies, como também de um "geofácies-clímax" que constitui um estágio final da evolução natural do geosistema. Na superfície de um geosistema, os geofácies desenham um mosaico mutante cuja estrutura e dinâmica traduzem fielmente os detalhes ecológicos e as pulsações de ordem biológica. O estudo dos geofácies deve sempre ser recolocado nessa perspectiva dinâmica.

Às vezes é indispensável conduzir a análise ao nível das microformas, na escala do metro quadrado ou mesmo do decímetro quadrado ( $7^{a}$ grandeza). Uma diáclase alargada pela dissolução (Pr. VIII, B), uma

18 Sur la notion de "mobilité écologique", cf. BERTRAND, G. Pour une étude géographique de la végétation R.G.P.S. - O., 1966, fasc. 2, p. $129-143$ 
cabeceira de nascente, um fundo de vale que o sol nunca atinge, uma face montanhosa, constituem igualmente biótopos cujas condições ecológicas são muitas vezes muito diferentes das do geosistema e do geofácies dentro das quais eles se acham. É o refúgio de biocenoses originais, às vezes relictuais ou endêmicas. Este complexo biótopo-biocenose, bem conhecido dos biogeógrafos, corresponde ao "geótopo", isto é, a menor unidade geográfica homogênea diretamente discernível no terreno; os elementos inferiores precisam da análise fracionada de laboratório.

A tabela 1 resume a classificação sintética das paisagens. De um lado, ela dá a escala e o lugar relativo de cada unidade global na hierarquia das paisagens como também os encadeamentos entre as diversas unidades. De outro, ela situa a série geosistemageofácies-geótopo em relação a um certo número de unidades e de classificação elementares.

\section{A DINÂMICA DA PAISAGEM}

Considerando a paisagem como uma entidade global, admite-se implicitamente que os elementos que a constituem participam de uma dinâmica comum que não corresponde obrigatoriamente à evolução de cada um dentre eles tomados separadamente. Somos levados então a procurar os mecanismos gerais da paisagem, em particular no nível dos geosistema e dos geofácies. O "sistema de erosão" de A. CHOLLEY inspirou diretamente esta ordem metodológica. Por que não alargar o conceito de "sistema de erosão" no conjunto da paisagem? Passar-se-ia assim de um fato estritamente geomorfológicos à noção mais vasta, mais completa e, sobretudo mais geográfica, de "sistema geral de evolução" da paisagem.

1- O exemplo de geosistema "mediterrâneo" da Baixa Liebana e do geosistema hiperoceânico das Sierras Planas (domínio cantábrico, região dos Picos de Europa)..$^{19}$ Os ravinamentos e os desnudamentos das vertentes são freqüentes na Baixa Liebana. As causas são primeiramente geomorfológicas (possante dissecção plio-quarternária nos xistos tenros, mantos superficiais espessos e instáveis) e fitogeográficos (tapete vegetal ralo e frágil de tipo relictual, isto é, em desequilíbrio bioclimático). A situação é agravada pelo sistema de valorização antrópica que multiplica os desmatamentos, os incêndios e a degradação das florestas claras, dos "maquis" e das "garrigues". Os solos são descontínuos e mal evoluídos (tipos "rankeriformes"). A geomorfogênese condiciona então a dinâmica de conjunto desse geosistema e domina o "sistema de evolução" da paisagem. Nas Sierras Planas os pastores asturianos destruíram a floresta para aumentar as áreas de pastoreio. Eles desencadearam uma cascata de processos pedológicos (podzolização, formação de turfa, hidromorfização) botânicos (extensão das "landes" ácidas) e às vezes mesmo geomorfológicos (movi-mentação dos mantos arenosos já pedogeneizados). A pedogênese tem aí um papel essencial e bloqueia atualmente a dinâmica geral da paisagem. Cada um desses geosistemas possui então um sistema de evolução diferente.

2- O sistema de evolução de uma unidade de paisagem, de um geosistema, por exemplo, reúne todas as formas de energia, complementares ou antagônicas que, reagindo dialeticamente umas em relação às outras, determinam a evolução geral dessa paisagem. Para as necessidades da análise, pode-se isolar três conjuntos diferentes no interior de um mesmo sistema de evolução. Com efeito, eles estão estreitamente solidários e se entrecruzam largamente:

- o sistema geomorfogenético tal qual o compreendem os geomorfologistas modernos que insistem no seu caráter "dinâmico" e "bioclimático" (J. TRICART);

- a dinâmica biológica que intervém ao nível do tapete vegetal e dos solos. Ela é determinada por toda a cadeia de reações ecofisiológicas que se manifestam por meio dos fenômenos de adaptação (ecótipos), de plasticidade, de disseminação, de concorrência entre as espécies ou as formações vegetais, etc... com prolongamentos no nível dos solos;

- o sistema de exploração antrópica que tem muitas vezes um papel determinante, seja ativando ou desencadeando erosões, seja somente modificando a vegetação ou solo (desmatamento, reflorestamento...).

3 - O sistema de evolução se define por uma série de agentes e de processos mais ou menos bem hierarquizados. Sem querer desenvolver aqui essa questão, podem ser distinguidos agentes naturais (climáticos, biológicos, etc...) que determinam processos naturais (ravinamentos, pedogênese, dinâmica ecofisiológica...) e agentes antrópicos (sociedades agropastoris, florestais...) dos quais dependem os processos antrópicos (desmatamento, incêndio, reflorestamento).

19 G. BERTRAND, op. cit., 1966, note 18, p. 236-248. 
Se não é nunca fácil apreciar a importância de determinado agente ou de determinado processo isolado, é no entanto possível classificar os sistemas de evolução em função do ou dos fatores dominantes (geomorgenético, antrópico...). É já um primeiro esboço de classificação das paisagens.

\section{A TIPOLOGIA DAS PAISAGENS}

Antes de classificar os geosistemas, é preciso darIhes nomes. Trata-se de definir, o mais breve possível, combinações ricas, muitas vezes únicas, que escapam às terminologias tradicionais. Na verdade, não são evitadas perífrases complicadas que a despeito de serem carregadas, não são sempre explícitas. A solução mais fácil consiste em designar o geosistema pela vegetação correspondente que representa muitas vezes a melhor síntese do meio. Como o nome de uma espécie não é suficiente, pode-se reter o da formação vegetal clímax e seu traço ecológico essencial (geosistema das florestas de carvalho atlântica acidófila, geosistema da floresta de faia montanhosa higrófila...). Todavia, não se pode fazer disso uma regra geral porque o tapete vegetal não é sempre o elemento dominante ou característico da combinação (por exemplo, para certos geosistemas de alta montanha ou das regiões áridas). Daí parece preferível reter o traço ou a associação geográfica característica, qualquer que seja sua natureza. Para maior precisão, acrescenta-se o nome do conjunto regional ao qual pertence o geosistema. Citemos a título de exemplo: para o vertente Norte do maciço Cantábrico Central, o geosistema hiperoceânico das Sierras Planas, o geosistema da montanha média oceânica silicosa da Sierra de Cuera, o geosistema do setor das gargantas calcárias com lenhosas, submediterrânea, o geosistema da alta montanha cárstica dos Picos de Europa. Para a montanha Negra ocidental: o geosistema das garupas super-florestadas da alta Montanha Negra, o geosistema sub-mediterrâneo acidófilo do "Cabardes"...

Os geofácies se definem facilmente no interior de cada geosistema porque eles correspondem sempre à uma combinação característica. Nesta escala, a vegetação fornece os melhores critérios, em particular sob a forma de agrupamentos fitosociológicos, com a condição de completar as definições com a ajuda dos outros elementos geográficos: geofácies das paredes calcárias de montanha com Potencialletalia caulescentis, geofácies do prado calcícola pastoril com Elynoseslerietea... A denominação dos geótopos obedece aos mesmos princípios: cabeça de nascentes com Osmunda regalis, tufas de Androsace em "auto-solo" húmico, turfeira com Sphagnum...
A relativa complexidade desse esboço taxonômico sublinha perfeitamente os problemas que aparecem na classificação global das paisagens. A dificuldade é menos de chegar a uma definição sintética do que adaptar o sistema de classificação ao fato de que a estrutura e a dinâmica das diferentes unidades mudam com a escala.

As tipologias estritamente fisionômicas (vertente florestal, planalto calcário com "garrigue") ou ecológicas (geosistema mediterrâneo, atlântico, montanhês...) não deram os resultados esperados. Elas são cômodas, mas carecem de rigor e sua generalização é difícil. A escolha caiu numa "tipologia dinâmica" que classifica os geosistema em função de sua evolução e que engloba por meio disso todos os aspectos das paisagens. Ela leva em conta três elementos: o sistema de evolução, o estágio atingindo em relação ao "clímax", o sentido geral da dinâmica (progressiva, regressiva, estabilidade). Esta tipologia se inspira portanto na teoria de biorestasia de H. ERHART. Foram distinguidos 7 tipos de geosistemas reagrupados em 2 conjuntos dinâmicos diferentes.

1- Os geosistemas em biostasia - trata-se de paisagens onde a atividade geomorfogenética é fraca ou nula. O potencial ecológico é, no caso, mais ou menos estável. O sistema de evolução é dominado pelos agentes e os processos bio-químicos: pedogênese, concorrência entre as espécies vegetais, etc... Aintervenção antrópica pode provocar uma dinâmica regressiva da vegetação e dos solos, mas ela nunca compromete gravemente o equilíbrio entre o potencial ecológico e a exploração biológica. Esses geosistemas em estado de biostasia classificam-se de acordo com sua maior ou menor estabilidade:

1a. Os geosistemas "climácicos", "plesioclimácicos" ou "subclimácicos" correspondem a paisagens onde o clímax é mais ou menos bem conservado, por exemplo, uma vertente montanhosa sombreada com "cobertura viva" (P. Birot) contínua e estável, formada por uma floresta de faia em solos brunos florestais "MulModer". A intervenção humana de caráter limitado, não compromete o equilibrilio de conjunto de geosistema. No caso de um desmatamento ou mesmo de um acidente "natural" (corrida de lama), observa-se bem rapidamente uma reconstituição da cobertura vegetal e dos solos; o potencial ecológico não parece modificado.

1b. Os geosistemas "paraclimácicos" aparecem no decorrer de uma evolução regressiva, geralmente de origem antrópica, logo que se opera um bloqueamento relativamente longo ligado a uma modificação parcial do potencial ecológico ou da exploração biológica. O melhor exemplo é o do geosistema hiperoceânico das Sierras Planas onde a floresta de carvalho destruída foi substituída por uma 
"lande" empobrecida em equilíbrio com os podzóis. A base aqui é de origem pedológica. A podzolização interdita todo retorno espontâneo do clímax florestal. A evolução não pode prosseguir senão artificialmente para uma outra forma de clímax (reflorestamento com resinosas após aração profunda).

1c. Os geosistemas degradados com dinâmica progressiva são bem freqüentes nas montanhas temperadas úmidas submetidas ao êxodo rural. Os territórios rurais cultivados passam ao abandono, com "landes", capoeiras e retorno a um estado florestal que é, na maior parte dos casos, diferente da floresta-clímax. É o caso de certas áreas declivosas dos territórios rurais pirenaicos do andar do carvalho séssil, que se cobrem de mata de tronco fino como aveleiras, bétulas, castanheiras e carvalhos diversos que não constituem obrigatoriamente a frente pioneira da floresta de carvalho-clímax anteriormente destruída.

1d. Os geosistemas degradados com dinâmica regressiva sem modificação importante do potencial ecológico representam as paisagens fortemente humanizadas onde a pressão humana não afrouxou ainda (montanhas cantábricas com economia agropastoril). A vegetação é modificada ou destruída, os solos são transformados pelas práticas culturais e o percurso dos animais. No entanto, o equilíbrio ecológico não é rompido malgrado um início de "ressecamento ecológico". As erosões mecânicas, sempre muito localizadas, guardam um caráter excepcional (por exemplo, ao longo dos caminhos vicinais).

2 - Os geosistemas em resistasia - A geomorfogênese domina a dinâmica global das paisagens. A erosão, o transporte e a acumulação dos detritos de toda a sorte (húmus, detritos vegetais, horizontes pedológicos, mantos superficiais e fragmentos de rocha in loco) levam a uma mobilidade das vertentes e a uma modificação mais ou menos possante do potencial ecológico. A geomorfogênese contraria a pedogênese e a colonização vegetal. No entanto, é preciso distinguir os 2 níveis de intensidade:

- $\quad$ de um lado, os casos de "resistasia verdadeira" ligados a uma crise geomorfoclimática capaz de modificar o modelado e o relevo. O sistema de evolução das paisagens se reduz então ao sistema de erosão clássico. A destruição da vegetação e do solo pode nesse caso ser total. Criase um geosistema inteiramente novo. Este fenômeno é freqüente nas margens das regiões áridas onde ele é muitas vezes acelerado pela exploração antrópica ("terras más" do Oeste dos EE.UU.). Pode tratar-se também de uma ruptura de equilíbrio "catastrófica", (por exemplo lava torrencial em montanha);

- por outro lado, os casos de "resistasia limitada" à "cobertura viva" da vertente, isto é, à parte superficial das vertentes: vegetação, restos vegetais, húmus, solos $e$, às vezes, manto superficial e lençóis freáticos epidérmicos. Esta evolução ainda não interessou suficientemente os geógrafos e os biogeógrafos. É certo que ela é quase negligenciável do ponto de vista geomorfológico porque ela não cria relevos, mesmo que anuncie às vezes os inícios de uma crise geomorfológica. No entanto, seu interesse é capital do ponto de vista biogeográfico porque ela mobiliza toda a parte biologicamente ativa da vertente. Pode-se qualificar esta erosão de "epidérmica" para bem distingui-la da erosão verdadeira ou "geomorfológica" e para evitar as confusões e as discussões inúteis que durante um certo tempo puseram em oposição os contra e a favor da erosão sob cobertura vegetal: eles não falavam do mesmo tipo de erosão nem de mesma cobertura vegetal e não se situavam na mesma escala. A erosão epidérmica tinha já sido definida sob o nome de erosão "biológica", ${ }^{20}$ mas este qualificativo era uma fonte de confusão. A tipologia dos geosistemas em resistência deve levar em conta todos esses fatos.

2a. Os geosistemas com geomorfogênese "natural". Nas regiões áridas e semi-áridas, assim como na alta montanha, a erosão faz parte do "clímax", isto é, ela contribui a limitar naturalmente o desenvolvimento da vegetação e dos solos (vertente montanhosa com talude de detritos móvel, superfície de um "glacis" de erosão alimentado por escoamento anastomosado de "oued").

$2 \mathrm{~b}$. Os geosistemas regressivos com geomorfogênese ligada à ação antrópica. Já se insistiu longamente sobre este aspecto da dinâmica das paisagens. É preciso encarar 3 casos: primeiro, os geosistemas em resistasia bioclimática cuja geomorfogênese é ativa pelo homem. Em seguida, os geosistemas marginais em "mosaico", isto é, com geofácies em resistasia e 
com geofácies em biostasia, caracterizados por um certo desequilíbrio e uma certa fragilidade natural. O exemplo típico é o do domínio mediterrâneo cuja degradação não está ligada somente ao fator antrópico. Enfim, os geosistemas regressivos e com potencial ecológico degradado que se desenvolvem por intervenção antrópica no seio das paisagens em plena biostasia (certas culturas de "plantation" em economia colonial).

Este esboço tipológico deve ser sumariamente colocado na dupla perspectiva do tempo e do espaço.

"No tempo", o problema mais delicado é considerar a parte das heranças. Com efeito, essas não são somente geomorfológicas e pedológicas, mas também florísticas e antrópicas. Seria preciso reconstituir a cadeia histórica dos geosistemas, sobretudo levando em conta a alternância e a duração respectiva das fases de equilíbrio biológico e das fases de atividade geomorfogenética. Os resultados combinados da análise de pólen, do exame dos depósitos superficiais e dos paleosolos, do estudo da ação humana, desde os inícios da vida pastoril e da agricultura, permitem às vezes obterse uma idéia precisa da dinâmica recente das paisagens. A região cantábrica se presta bem a essa pesquisa graças aos trabalhos dos pré-historiadores, dos palinólogos e dos fitosociólogos.

"No espaço", a justaposição dos geosistemas é um fato geral. No entanto, os geosistemas com equilíbrio biológico ocorrem, sobretudo, nas zonas temperadas e tropicais úmidas, assim como em certas regiões de planície. A alta montanha e as diagonais áridas abrigam, sobretudo, os geosistemas com mais ou menos grande atividade geomorfogenética. A exploração antrópica está em vias de perturbar esta distribuição essencialmente bioclimática estendendo os geosistemas em desequilíbrio biológico. Mas a erosão "geomorfológica", muitas vezes rápida e espetacular, não se exerce senão em superfícies reduzidas. Em compensação, o verdadeiro perigo do ponto de vista da organização do espaço é a erosão "epidérmica" que, de forma às vezes insidiosa, arranha a película viva das vertentes em setores extensos sem que se preste a ela uma real atenção. $O$ estudo da distribuição espacial dos geosistemas é pois um problema de geografia "ativa" que vem reforçar o interesse da pesquisa cartográfica.

\section{A CARTOGRAFIA DAS PAISAGENS}

A representação cartográfica das paisagens exige um inventário geográfico completo e relativamente detalhado. A análise deve ao menos descer até o nível dos geofácies mesmo se eles não devem figurar na carta. O essencial do trabalho se efetua no terreno: levantamentos geomorfológicos, pedológicos e fitogeográficos, exame das águas superficiais, observações meteorológicas elementares, inquéritos sobre o sistema de valorização econômica (gestão florestal, percursos pastoris, direitos de uso, etc...). Essas informações e levantamentos temáticos são completados pelos trabalhos de arquivos e inquéritos diversos (cadastro, serviços administrativos, etc...). A consulta da bibliografia especializada é, bem entendido, indispensável, mas ela é muitas vezes difícil de ser utilizada por causa da diferença de ponto de vista. Para orientar toda essa documentação volumosa e disparatada, é preciso escolher uma linha mestra. Ela é fornecida pelo tapete vegetal cujo levantamento sistemático a 1/50.000, segundo um método simplificado, intermediário entre o do Serviço da Carta da Vegetação a 1/200.000 da França e o da Carta da Vegetação a 1/100.000 dos Alpes de P. Ozenda, serve de base à cartografia global das paisagens. A interpretação das fotografias aéreas constitui um apoio precioso porque ela fornece uma visão sintética e instantânea das paisagens. Ensaios cartográficos foram realizados em diversas escalas (contentemo-nos em lembrar aqui o método seguido e os resultados obtidos no curso das pesquisas de tese e de direção de mestrados).

$\mathrm{Na}$ escala média (1/100.000 e 1/200.000) podese cartografar os geosistemas de maneira satisfatória com a condição de renunciar à acumulação dos sinais analíticos e de escolher uma representação sintética. Cada geosistema corresponde a um lugar cuja cor e respectiva trama são escolhidas em função da dinâmica do geosistema, (exemplo: azul para os geosistemas climácicos, verde para os geosistemas paraclimácicos, amarelo para os geosistemas regressivos com degradação antrópica dominante, vermelho para os geosistemas com evolução essencialmente geomorfológica). Os jogos de trama permitem variar essa tipologia. Na carta 1/200.000 das montanhas cantábricas centrais (cobrindo mais ou menos $6.000 \mathrm{Km}^{2}$ ) foram determinados 32 geosistemas. ${ }^{21}$

$\mathrm{Na}$ escala grande $1 / 20.000$, pode-se facilmente cartografar os geofácies no interior dos geosistemas. A cor ou a variação na cor de cada geosistemas indica a situação dinâmica em relação ao clímax (geofáciesclimax em azul, geofácies degradado em amarelo ou em vermelho). Pode-se assim escolher um tema, por exemplo, como as relações entre a cobertura vegetal e a erosão "epidérmica". 
A geografia física global não está destinada a substituir, nem mesmo a concorrer com os estudos especializados tradicionais dos quais, aliás, ela se nutre. Ela constitui uma pesquisa paralela que aproxima, confronta e completa os dados da análise e que coloca cada elemento no seu complexo de origem, estudando mais especialmente as combinações geográficas e sua dinâmica global. Sua função essencial é, portanto, de "redescobrir" a geografia física tradicional e de fazer diretamente apelo às ciências biológicas e às ciências humanas. Mas ainda, dando o meio de descrever, de explicar e de classificar cientificamente as paisagens, ela se abre naturalmente para os problemas de organização do espaço não urbanizado. Mas este estudo global dos meios naturais não pode ser conduzido somente pelos geógrafos. Ele não pode expandir-se senão na pesquisa e na reflexão interdisciplinar. 